\title{
National incidence of eyelid cancer in Ireland (2005-2015)
}

\author{
Clare Quigley $^{1} \cdot$ Sandra Deady $^{2} \cdot$ Emily Hughes $^{1} \cdot$ Elizabeth McElnea $^{3} \cdot$ Lina Zgaga $^{4} \cdot$ Shivona Chetty $^{1}$
}

Received: 25 November 2018 / Revised: 23 February 2019 / Accepted: 13 March 2019 / Published online: 11 April 2019

(c) The Royal College of Ophthalmologists 2019

\begin{abstract}
Aims We report on the incidence of cutaneous eyelid tumours in Ireland over the 11-year-period from 2005 to 2015, we identify associations between demographic factors and cutaneous eyelid tumour risk.

Methods Skin cancers, including basal cell carcinoma (BCC), squamous cell carcinoma (SCC), melanoma, and other cancers, located on the eyelid or canthus according to ICD-10 coding, as registered by the National Cancer Registry of Ireland (NCRI), were captured from the period 2005 to 2015. Age standardised rates (ASR) were calculated according to the European Standard Population (2013). Longitudinal data analysis using linear regression, and associations with age and sex were evaluated with the statistics program $R$.

Results There were 4824 patients diagnosed with eyelid BCC during the study period, the ASR in men and women was mean 15.87 and 13.49 per 100,00, respectively. The relative risk for eyelid BCC in men compared with women was 1.18, age was associated with incidence. There were 528 patients diagnosed with SCC; the ASR of eyelid SCC in men and women was 2.10 and 1.39 per 100,000 , respectively, and increased in women annually $(\beta=0.07, p=0.0005)$. The relative risk for eyelid SCC in men compared with women was 1.51 , and age was exponentially associated with SCC. Melanoma and other eyelid tumours were uncommon-50 and 55 cases, respectively.

Conclusion Incidence of both BCC and SCC increases with age and male sex. The incidence of eyelid SCC is increasing in women, and under age 50, eyelid BCC is more common in women than men.

Synopsis We describe the recent incidence of eyelid cancers in Ireland, from National Cancer Registry Data. We find eyelid $\mathrm{BCC}$, and also SCC, are associated with increased age. Rate of eyelid SCC is increasing in women.
\end{abstract}

\section{Introduction}

Skin cancer is the most common type of cancer in humans [1]. Basal cell carcinoma (BCC) is the most common skin cancer, of which $10 \%$ are estimated to occur in the periocular skin $[2,3]$. Squamous cell carcinoma (SCC) is the second most common skin cancer [4]. Skin cancers affecting the periocular skin are more detrimental than elsewhere, due to both the morbidity or uncommonly mortality, which may arise from local invasion [5], and also the morbidity associated with

Clare Quigley

quigleyclare@gmail.com

1 Sligo University Hospital, Sligo, Ireland

2 National Cancer Registry Ireland, Cork Airport Business Park, Cork, Ireland

3 Royal Victorian Eye and Ear Hospital, Melbourne, VIC, Australia

4 Department of Public Health \& Primary Care, Trinity College Dublin, Dublin, Ireland treatment, as excision can involve removal of the eyelids, or a significant amount of periocular skin [6]. Compared to other skin regions periocular BCCs grow more rapidly [7].

UV radiation, especially for fair-skinned persons, is the primary aetiology for development of keratinocyte carcinoma [8] and melanoma [9]. As with most cancers, skin cancer is more common in older people [4]. There is predicted to be a substantial increase in the older population over the age 65 in Ireland, which is projected to more than double from a population of 532,000 older persons in 2011, to 1.4 million in 2046 [10]. The National Cancer Registry of Ireland (NCRI) predicts a commensurate increase in the incidence of skin cancer [11].

The incidence of skin cancer worldwide, including keratinocyte carcinoma and melanoma, is indeed reported to be increasing; the rate, however, varies significantly, with highest rates of BCC reported in Australia ( $>1000$ per $100,000)$ and lowest rates reported in parts of Africa $(<1$ per $100,000)[12,13]$. The UK National Institute for Health and Clinical Excellence has recommended that the epidemiology of skin cancer is studied further [14]. We aimed to estimate the current burden of eyelid skin cancer in Ireland, to inform 
service provision. We sought national data, from the NCRI, a publicly funded body, which has recorded information on all cancers occurring in Ireland since 1994 [15].

\section{Materials and methods}

Data from the NCRI were accessed to determine the incidence of eyelid tumours from annual registration data. Data from the period 2005-2015 were retrieved, during which period the population nationally increased from 4.13 million in 2005 , to 4.64 million in 2015 [16]. All eyelid tumours were detected according to specification of ICD-03 topography codes [17], which include the tumour site "eyelid", coded as C44.1. This tumour site also incorporates the medial and lateral canthus.

By convention, the site of only the first BCC and first SCC in any individual patient is registered. Consequently, patients who first developed a BCC or SCC elsewhere prior to biopsy of an eyelid tumour of the same type, were not captured by our data. This removed the possibility of duplication in patients who may have had multiple biopsies carried out of an eyelid tumour, e.g. incision biopsy followed by excision biopsy, and prevented the 'double counting' of patients with multiple eyelid cancers of the same type or recurrences of tumour, thus capturing only new cases and providing a measure of incidence. Eyelid melanoma was an exception to this- the site of each melanoma is recorded, resulting in capture of all cases.

Tumour histology data, and demographic data including patient age and sex, were also collected, according to data release policy of the NCRI.

\section{Statistical analysis}

The incidence rate of eyelid cancers per year was determined. Age-standardised incidence rates (ASRs) per 100,000 population per year were calculated according to the European Standard population (2013). Linear regression was carried out to analyse for significant change in the ASR of eyelid BCC and SCC. The year was used as a continuous variable in the model to test for a longitudinal trend in incidence, with significance level set as $p<0.05$. Relative risk for men compared with women was calculated. Data analysis was carried out using the statistics program $\mathrm{R}$ [18].

\section{Results}

\section{Eyelid basal cell carcinoma}

Over the 11-year-period studied (2005-2015), there were 4824 cases of eyelid basal cell carcinoma (BCC) being the first BCC diagnosed-2408 in men (annual range 178256) and 2416 in women (annual range 185-271), see Table 1. The ASR for BCC was, in men, 15.87 per 100,000 (95\% confidence interval (CI) 15.54-16.21), and in women, 13.49 per 100,000 (95\% CI 13.22-13.76), see Fig. 1. The annual BCC ASR did not change significantly over time in men or women.

Overall there was a higher risk in men compared with women for eyelid BCC, relative risk was 1.18 (95\% CI $1.06-1.29)$, though under age 60 , the sex association was reversed, see Table 2. The incidence of eyelid BCC rose with age, in both men and women, see Fig. 2a, with the rate in men and women approximately doubling per decade between the age of 50 and 80 , and reducing after age 90 .

\section{Eyelid squamous cell carcinoma}

There were 528 cases of eyelid SCC being their first skin SCC diagnosed-290 in men (annual range 19-39), and 238 in women (annual range 13-29), see Table 1. The ASR for SCC was, in men, 2.10 per 100,000 (95\% CI 1.98 to 2.23 ), and in women, 1.39 per 100,000 (95\% CI 1.30 to 1.48), see Fig. 3. The ASR increased significantly in women, at a rate of 0.07 cases per 100,000 annually $(\beta=$ $0.07, p=0.0005$ ), with a non-significant increase in men $(\beta=0.6, p=0.18)$.

There was increased risk of SCC in men; relative risk for men compared to women was 1.51 (95\% CI 1.32-1.71), see Table 2. The incidence of eyelid SCC rose exponentially with age, shown in Fig. 2b, with approximate doubling of rate of SCC per decade from age 50 to 90 , followed by a reduction in both men and women after age 90 .

Table 1 New cases of eyelid BCC and eyelid SCC in males and females 2005-2015 reported by the national cancer registry of Ireland (NCRI)

\begin{tabular}{|c|c|c|c|c|c|c|}
\hline \multirow[t]{2}{*}{ Year } & \multicolumn{3}{|c|}{ Eyelid BCC } & \multicolumn{3}{|c|}{ Eyelid SCC } \\
\hline & Males & Females & Combined & Males & Females & Combined \\
\hline 2005 & 187 & 192 & 379 & 19 & 13 & 32 \\
\hline 2006 & 208 & 185 & 393 & 26 & 15 & 41 \\
\hline 2007 & 178 & 203 & 381 & 22 & 18 & 40 \\
\hline 2008 & 203 & 199 & 402 & 24 & 20 & 44 \\
\hline 2009 & 210 & 205 & 415 & 20 & 18 & 38 \\
\hline 2010 & 199 & 207 & 406 & 26 & 23 & 49 \\
\hline 2011 & 238 & 271 & 509 & 34 & 24 & 58 \\
\hline 2012 & 239 & 243 & 482 & 19 & 28 & 47 \\
\hline 2013 & 256 & 218 & 474 & 26 & 24 & 50 \\
\hline 2014 & 246 & 253 & 499 & 39 & 26 & 65 \\
\hline 2015 & 244 & 240 & 484 & 35 & 29 & 64 \\
\hline Total & 2408 & 2416 & 4824 & 290 & 238 & 528 \\
\hline
\end{tabular}




\section{Other eyelid tumours}

There were 50 eyelid malignant melanomas diagnosed during the study period-29 in women, and 21 in men, approximating an annual incidence of 0.1 per 100,000 overall. There were 55 cases of other eyelid tumours, including sebaecous adenocarcinoma, Merkel cell carcinoma, unspecified carcinomas and other tumours-29 in women and 26 in men.

\section{Discussion}

We present heretofore unreported data on eyelid cancer registrations in Ireland, which establishes a baseline esti-

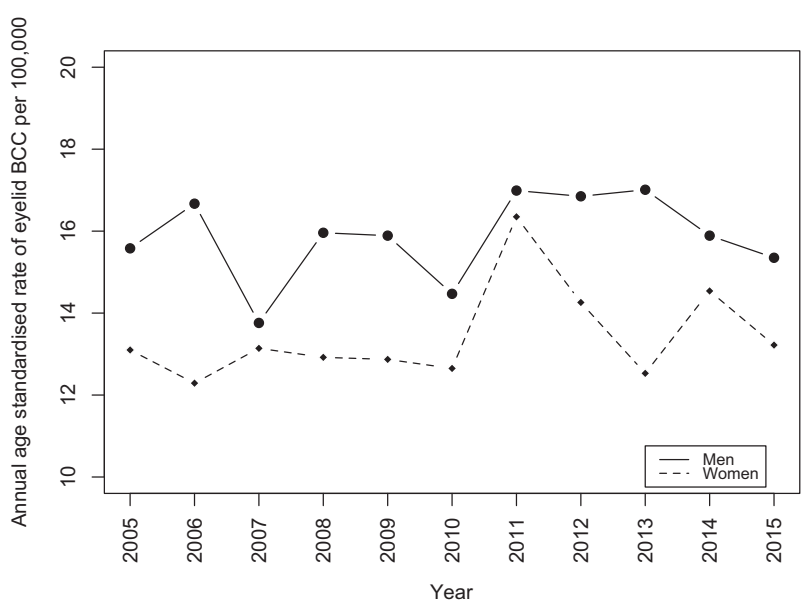

Fig. 1 Annual age standardised rate of eyelid basal cell carcinoma in men and women per 100,000, 2005-2015, Ireland mate of rate of eyelid skin cancer, and highlights new trends in demographic risk factors in the population. We demonstrate that periocular BCC and SCC are associated with older age and male sex, and SCC is increasing nationally in women, whereas the rate of eyelid $\mathrm{BCC}$ is not changing significantly. Eyelid BCC was more common in women than men under age 60. Our data is especially important as there are skin cancer prevention initiatives which have been found to be highly cost-effective [19].

In both men and women the development of BCC and more particularly SCC was associated with increased age, in keeping with previous reports from cancer registries in England [20, 21]. This differential age profile may be due to the aetiology of the keratinocyte carcinomas, whereby cumulative UV exposure, and also immunosuppression are implicated in SCC, whereas development of BCC is related to intermittent high-dose sun exposure [22].

Overall periocular BCC was more common in men, with a relative risk of 1.2 for men compared with women. In the under 60-year-old cohort, the sex association was reversed, with BCC more common in women. This differential sex association with eyelid BCC according to age cohort has also been described in England [20], and increased keratinocyte carcinoma has been described recently in younger women; this may be secondary to greater UV exposure, including from tanning beds, and may also be contributed to by greater self-surveillance and seeking of medical attention amongst women versus men, in this age group [23]. There are reports of a rapid and disproportionate increase in BCC in young women in Denmark, the Netherlands, and the US $[22,24,25]$, and in the UK, a loss of an association of BCC
Table 2 Relative risk in men compared with women of eyelid basal cell carcinoma (left) and squamous cell carcinoma (right) with respect to age and overall during the study period

\begin{tabular}{llll}
\hline & Age band & $\begin{array}{l}\text { Eyelid BCC relative risk of men } \\
\text { compared with women }\end{array}$ & $\begin{array}{l}\text { Eyelid SCC relative risk of men } \\
\text { compared with women }\end{array}$ \\
\hline Age band & $<50$ & $0.97(0.96-0.99)$ & $1.21(1.16-1.26)$ \\
& $50-59$ & $0.91(0.87-0.96)$ & $1.17(1.13-1.21)$ \\
& $60-69$ & $1.07(1.04-1.11)$ & $1.48(1.37-1.59)$ \\
& $70-79$ & $1.19(1.09-1.28)$ & $1.43(1.17-1.68)$ \\
& $80-89$ & $1.55(1.28-1.83)$ & $1.40(0.93-1.86)$ \\
Years & $2005-$ & $2.10(1.55-2.65)$ & $1.86(1.61-2.10)$ \\
& 2006 & $1.27(1.12-1.42)$ & $1.55(1.33-1.77)$ \\
& $2007-$ & $1.14(1.03-1.25)$ & $1.42(1.22-1.63)$ \\
& 2008 & & $1.31(1.15-1.46)$ \\
& $2009-$ & $1.19(1.07-1.31)$ & $1.54(1.35-1.74)$ \\
& 2010 & & $1.51(1.32-1.71)$ \\
\hline & $2011-$ & $1.11(1.01-1.21)$ & \\
\hline Mears & 2012 & &
\end{tabular}

Relative risk values are followed by $95 \%$ CIs in brackets 


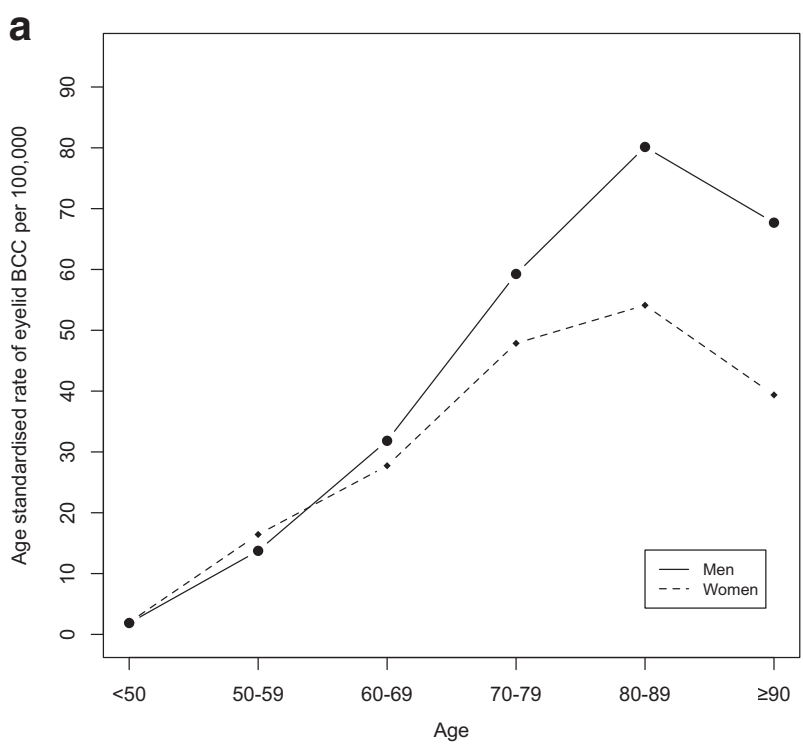

b

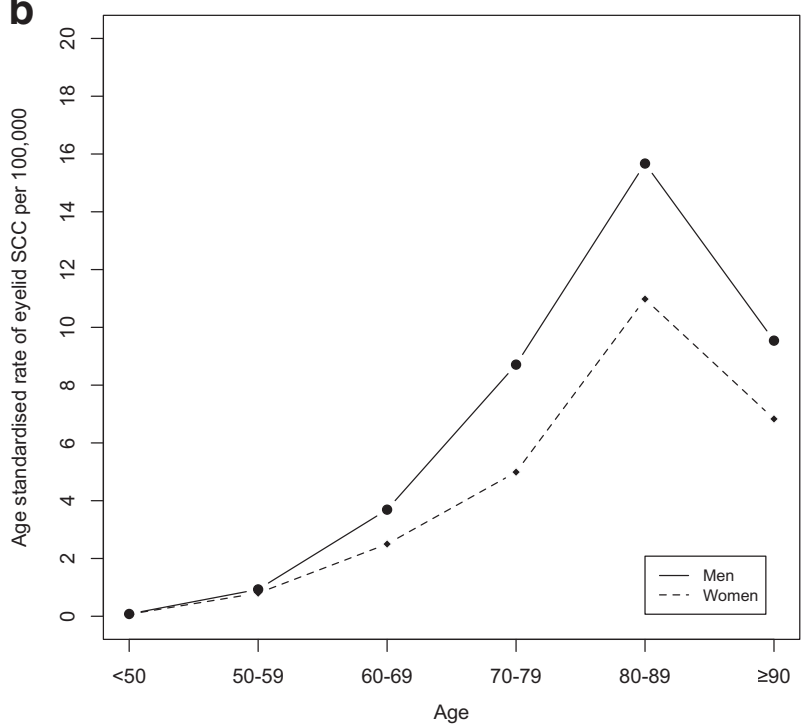

Fig. 2 a. Age standardised rate of eyelid basal cell carcinoma in men and women by age, per 100,000, 2005-2015, Ireland, b. Age standardised rate of eyelid squamous cell carcinoma in men and women by age, per 100,000, 2005-2015, Ireland

with male sex in the younger population [26]. Longitudinal studies are required to determine whether the association with women compared to men we observe in this age cohort carries forward in older age.

Eyelid SCC was more common in men, in all age groups, with an overall relative risk of 1.5 . This finding has been reported in other populations, though with a greater sex association, including a relative risk for men compared to women of 1.9 in England [21], and 2.0 in Australia [6], for eyelid SCC.

The ASR of eyelid BCC was found to be constant in both men and women over the study period. In comparison, there was an increase in rate of eyelid SCC in women by a mean rate of $3 \%$ annually, though no change in men. An increase in

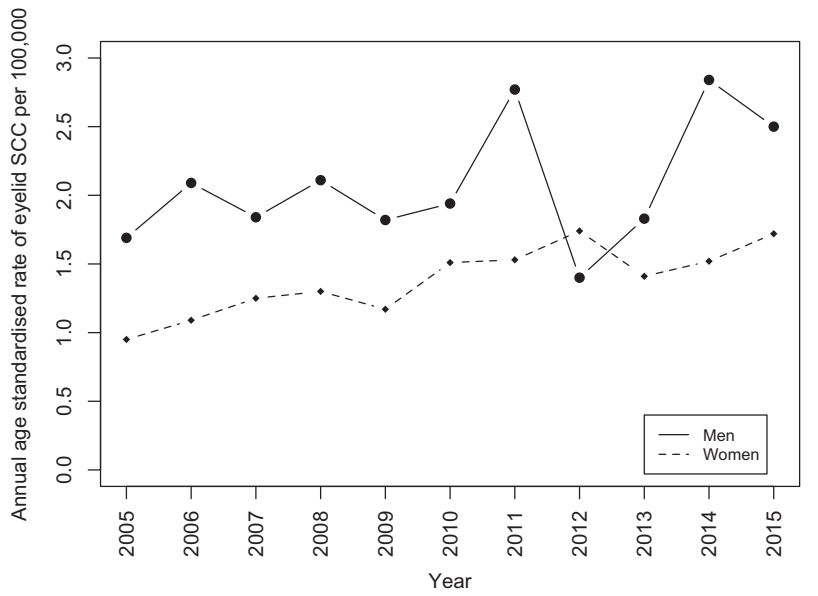

Fig. 3 Annual age standardised rate of eyelid squamous cell carcinoma in men and women per 100,000, 2005-2015, Ireland

skin SCC in other Caucasian populations has been described, in Northern Ireland, England, Canada, the Netherlands, and Australia [21, 27-30]. There are a variety of possible contributing factors to our finding of increasing SCC in womenincreased awareness and surveillance for skin cancer, with subsequent increased detection may be relevant. Greater incidence due to increased sun seeking behaviour, and also due to population ageing may also be important.

The annual ASR we report, 15.87 and 13.49 per 100,00 in men and women, respectively, for eyelid BCC, and 2.10 and 1.39 in men and women, respectively, for eyelid SCC, is over twice that was described in recent reports from England, which described an annual overall ASR of 0.63 for eyelid SCC, and rates of 4.51 and 4.53 per 100,000 in men and women, respectively, for eyelid BCC $[20,21]$. The accuracy of the reporting of $\mathrm{BCC}$ in the $\mathrm{UK}$ has been previously examined; a 2013 report compared the reporting of $\mathrm{BCC}$ rate from cancer registry data, versus histopathology data in a representative area in England, and showed that the true BCC rate may be over twice that reported by local cancer registry data [31]. Another analysis has shown discrepancies between skin cancer registration, and under-detection effecting especially BCC, in the cancer registries in the UK [32]. This may contribute to the higher rate of eyelid BCC and SCC we observe, although similar limitations may apply to the Irish Cancer Registry data on keratinocyte skin cancers. Further complicating comparisons, the rate of BCC and SCC varies according to a population's skin pigment, and also latitude, among other factors $[33,34]$. The reported rate of BCC varies substantially even within England-in a report of eyelid BCC, the largest Cancer Registry in England, the Thames Cancer Registry, which covers over 13 million people, reported less eyelid BCC than any other Cancer Registry in England, over the period 2000-2010 [20].

We found that eyelid malignant melanoma and other eyelid cancers were uncommon, with the rate of eyelid 
melanoma approximating 1 per million annually. Malignant melanoma however accounts for most deaths from skin cancer [35], increasing the importance of monitoring its rate.

Limitations of our study include a likelihood of underestimation of the true rate of cutaneous eyelid cancers, as only the body site of the first BCC or SCC diagnosed in a given patient is recorded. Therefore, subsequent eyelid cancers of the same type, in the same patient, are not captured. For the same reason the data presented here omits patients with tumour recurrence. The study did not analyse subgroups of patients according to race, limiting the application of our conclusions in other populations. The role of socio-economic status was not assessed in this study, however, it may be important, as keratinocyte carcinoma in Ireland has been found to be positively associated with socio-economic status [36].

\section{Conclusion}

We show that there is increased risk of eyelid cancer in the elderly, and in men. Eyelid SCC is increasing in women, and younger women are at greater risk of eyelid BCC.

\section{Summary}

\section{What was known before}

- Eyelid cancers, including BCC and SCC, are more common in older people, and more common in men.

\section{What this study adds}

- Eyelid SCC is increasing in women, and in younger cohorts, eyelid BCC is more common in women than in men.

\section{Compliance with ethical standards}

Conflict of interest The authors declare that they have no conflict of interest.

Publisher's note: Springer Nature remains neutral with regard to jurisdictional claims in published maps and institutional affiliations.

\section{References}

1. Raasch B, Maclennan R, Wronski I, Robertson I. Body site specific incidence of basal and squamous cell carcinoma in an exposed population, Townsville, Australia. Mutat Res. 1998;422:101-6.

2. Green A. Changing patterns in incidence of non-melanoma skin cancer. Epithel Cell Biol. 1992;1:47-51.

3. Salomon J, Bieniek A, Baran E, Szepietowski JC. Basal cell carcinoma on the eyelids: own experience. Dermatol Surg. 2004;30(2 Pt 2):257-63.

4. Trakatelli M, Ulrich C, del Marmol V, Euvrard S, Stockfleth E, Abeni D. Epidemiology of nonmelanoma skin cancer (NMSC) in Europe: accurate and comparable data are needed for effective public health monitoring and interventions. $\mathrm{Br} \mathrm{J}$ Dermatol. 2007;156(Suppl 3):1-7.

5. Soysal HG, Markoc F. Invasive squamous cell carcinoma of the eyelids and periorbital region. Br J Ophthalmol. 2007;91:325-9.

6. Donaldson MJ, Sullivan TJ, Whitehead KJ, Williamson RM. Squamous cell carcinoma of the eyelids. $\mathrm{Br} \mathrm{J}$ Ophthalmol. 2002;86:1161-5.

7. Tan E, Lin FP, Sheck LH, Salmon PJ, Ng SG. Growth of periocular basal cell carcinomas. Br J Dermatol. 2015;172:1002-7.

8. Xiang F, Lucas R, Hales S, Neale R. Incidence of nonmelanoma skin cancer in relation to ambient UV radiation in white populations, 1978-2012: empirical relationships. JAMA Dermatol. 2014;150:1063-71.

9. Koh HK, Geller AC, Miller DR, Grossbart TA, Lew RA. Prevention and early detection strategies for melanoma and skin cancer. Current status. Arch Dermatol. 1996;132:436-43.

10. Office CS. Population and Labour Force Projections 2016-2046, 2013.

11. Ireland NCR. Cancer projections for Ireland 2015-2040. Cork, 2014.

12. Lomas A, Leonardi-Bee J, Bath-Hextall F. A systematic review of worldwide incidence of nonmelanoma skin cancer. Br J Dermatol. 2012;166:1069-80.

13. Nikolaou V, Stratigos AJ. Emerging trends in the epidemiology of melanoma. Br J Dermatol. 2014;170:11-9.

14. Excellence NIfHaC. Improving outcomes for people with skin tumours including melanoma. 2006.

15. Ireland NCR. About us. 2018. https://www.ncri.ie/about/history. Accessed 18 May 2018.

16. Office CS. Population and migration estimates April 2016, 2016.

17. Organization WH. International Classification of Diseases for Oncology., 3rd ed. Topographical Codes. 2018. http://codes.ia rc.fr/topography. Accessed 18 May 2018.

18. Team RC. R: A language and environment for statistical computing. 2016. https://www.r-project.org/.

19. Gordon LG, Rowell D. Health system costs of skin cancer and cost-effectiveness of skin cancer prevention and screening: a systematic review. Eur J Cancer Prev. 2015;24:141-9.

20. Saleh GM, Desai P, Collin JR, Ives A, Jones T, Hussain B. Incidence of eyelid basal cell carcinoma in England: 2000-2010. Br J Ophthalmol. 2017;101:209-12.

21. Wawrzynski J, Tudge I, Fitzgerald E, et al. Report on the incidence of squamous cell carcinomas affecting the eyelids in England over a 15-year period (2000-2014). Br J Ophthalmol. 2018;102:1358-61.

22. Birch-Johansen F, Jensen A, Mortensen L, Olesen AB, Kjaer SK. Trends in the incidence of nonmelanoma skin cancer in Denmark 1978-2007: rapid incidence increase among young Danish women. Int J Cancer. 2010;127:2190-8.

23. Purdue MP, Freeman LE, Anderson WF, Tucker MA. Recent trends in incidence of cutaneous melanoma among US Caucasian young adults. J Invest Dermatol. 2008;128:2905-8.

24. de Vries E, Louwman M, Bastiaens M, de Gruijl F, Coebergh JW. Rapid and continuous increases in incidence rates of basal cell carcinoma in the southeast Netherlands since 1973. J Invest Dermatol. 2004;123:634-8. 
25. Christenson LJ, Borrowman TA, Vachon CM, et al. Incidence of basal cell and squamous cell carcinomas in a population younger than 40 years. JAMA. 2005;294:681-90.

26. Bath-Hextall F, Leonardi-Bee J, Smith C, Meal A, Hubbard R. Trends in incidence of skin basal cell carcinoma. Additional evidence from a UK primary care database study. Int J Cancer. 2007;121:2105-8.

27. McLean DI, Phillips N, Zhou Y, Gallagher R, Lee TK. 40-year trends in skin cancer in British Columbia, Canada, 1973 to 2003. J Cutan Med Surg. 2012;16:83-91.

28. Hoey SE, Devereux CE, Murray L, et al. Skin cancer trends in Northern Ireland and consequences for provision of dermatology services. Br J Dermatol. 2007;156:1301-7.

29. Hollestein LM, de Vries E, Nijsten T. Trends of cutaneous squamous cell carcinoma in the Netherlands: increased incidence rates, but stable relative survival and mortality 1989-2008. Eur J Cancer. 2012;48:2046-53.
30. Staples MP, Elwood M, Burton RC, Williams JL, Marks R, Giles GG. Non-melanoma skin cancer in Australia: the 2002 national survey and trends since 1985. Med J Aust. 2006;184:6-10.

31. Levell NJ, Igali L, Wright KA, Greenberg DC. Basal cell carcinoma epidemiology in the UK: the elephant in the room. Clin Exp Dermatol. 2013:38:367-9.

32. Goodwin RG, Holme SA, Roberts DL. Variations in registration of skin cancer in the United Kingdom. Clin Exp Dermatol. 2004;29:328-30.

33. Verkouteren JAC, Ramdas KHR, Wakkee M, Nijsten T. Epidemiology of basal cell carcinoma: scholarly review. Br J Dermatol. 2017;177:359-72.

34. Kallini JR, Hamed N, Khachemoune A. Squamous cell carcinoma of the skin: epidemiology, classification, management, and novel trends. Int J Dermatol. 2015;54:130-40.

35. Society AC. Cancer facts \& figures. Atlanta; 2003.

36. Ireland NCR. Cancer Trends no 20. Non-melanoma skin cancer. 2013. 